\title{
A comparative assessment of safety and tolerability of metoprolol versus carvedilol in patients of chronic stable angina
}

\author{
Megha Bansal*, Manju Gari, Manisha Varshney
}

Department of Pharmacology and Therapeutics, Rajendra Institute of Medical Sciences, Ranchi, Jharkhand, India

\author{
Received: 19 February 2020 \\ Revised: 04 April 2020 \\ Accepted: 07 April 2020 \\ *Correspondence: \\ Dr. Megha Bansal, \\ Email: megha258036@gmail.com
}

Copyright: $@$ the author(s), publisher and licensee Medip Academy. This is an open-access article distributed under the terms of the Creative Commons Attribution Non-Commercial License, which permits unrestricted non-commercial use, distribution, and reproduction in any medium, provided the original work is properly cited.

\begin{abstract}
Background: Angina pectoris is a clinical manifestation characterized by chest pain typically in substerum radiating to left arm, jaw, back lasting for 1-5 minutes and is relieved by rest. Beta blockers are one of the drugs indicated in angina. The aim of the study is to compare safety and tolerability of metoprolol and carvedilol in patients of chronic stable angina.

Methods: The study done is randomized, open label, parallel type where tablet carvedilol and tab metoprolol is given in a group of 50 patients each. The patients were followed thereafter on 8th, 16th, 24th week to study safety in terms of haematological parameters like complete blood count, liver function tests, renal function tests, serum sodium, serum potassium, fasting blood glucose, 2 hours post prandial blood glucose, HbA1C, and Lipid profile and tolerability in terms of side effects. The study was conducted for one year and the data was assessed by relevant statistical analysis where $\mathrm{p}$ value $<0.05$ was considered significant.

Results: It was seen that the disease was most common in the age group of 51-60 years with male preponderance, and carvedilol was found to cause non-significant decrease in Serum Triglyceride with no change in total cholesterol, HDL-C, LDL-C was found. No significant changes were observed in metoprolol group. There was no significant difference observed when blood sugar profile and other haematological parameters were considered. Both drugs were considered to be equally tolerable.

Conclusions: Compared with carvedilol and metoprolol in patients of chronic stable angina, carvedilol resulted in better lipid profile whereas metoprolol showed no changes in lipid parameters.
\end{abstract}

Keywords: Carvedilol, Metoprolol, Chronic stable angina, Angina

\section{INTRODUCTION}

Ischemic heart disease (IHD) is a condition where there is an imbalance between myocardial oxygen demand and myocardial oxygen supply. Coronary artery disease is becoming major health concern and has become increasingly prevalent nowadays. The Registrar General of India reported that CHD led to $17 \%$ of total deaths and $26 \%$ of adult deaths in 2001-2003, which increased to $23 \%$ of total and $32 \%$ of adult deaths in $2010-2013 .{ }^{1}$ The most common cause of ischemic heart disease is atherosclerotic disease of epicardial coronary artery. ${ }^{2}$ Angina pectoris is a clinical manifestation characterized by chest pain in the substernum region lasting for 1-5 minutes and is relieved by rest. $\beta$ blockers are the only drug class that is effective in reducing the severity and frequency of attacks of exertional angina, they act by reducing myocardial oxygen demand both during exercise and rest by reducing cardiac work load. They also reduce mortality by decreasing the incidence of sudden cardiac death associated with myocardial infarction and ischemia. Carvedilol is $\beta 1, \beta 2$ receptor antagonist with some capacity to block $\alpha$ receptor as well. 
The favorable effects of carvedilol are provided by its anti-oxidant, anti-inflammatory and its anti-apoptotic activities. Carvedilol prevents lipid peroxidation, modification of oxidation of low-density lipoprotein (LDL) particles, preserves the function of nitric oxide (NO) dependent vasodilatation. In contrast, Metoprolol is a selective $\beta 1$ receptor blocker, which is devoid of intrinsic sympathomimetic property and membrane stabilizing activity.

\section{METHODS}

After taking approval from the Ethics Committee, the study was conducted on 100 patients with 50 patients in each group of metoprolol and carvedilol. The patients who attended cardiology outpatient department in RIMS, Ranchi in the age group of 50-60 years of both sexes with the diagnosis of chronic stable angina were included in the study. The patients who had history of intolerance to beta blockers, patients of variant angina, unstable angina, myocardial infarction, history of alcohol abuse, active myocarditis, primary valve diseases, congenital heart disease, concomitant disease which adversely influence the prognosis and/or impair exercise capacity (e.g. malignancy, musculoskeletal disease), advanced heart block, brady arrythmias, Raynaud phenomenon, history of mental depression, reversible airway obstruction in patients with chronic lung disease, pregnant women, lactating mother were excluded from the study.

After assessing the inclusion and exclusion criteria, the patients were randomized into two groups of 50 patients in each group after obtaining the informed consent. The dose of tablet metoprolol was given at a range of 25-50 $\mathrm{mg}$ in two divided doses and tablet carvedilol at a range of (3.125-6.25) $\mathrm{mg}$ in two divided doses. The dose was decided by the clinician depending on the patient's disease status. The patients were followed on $24^{\text {th }}$ week with the following investigations $\mathrm{CBC}$, liver function tests, renal functions tests, fasting blood sugar, post prandial blood sugar, HbA1C, serum sodium, serum potassium. The study period was taken for one year from May 2018 to 2019.

Statistical analysis was performed using SPSS software. The t-test was used to compare the demographic profile and clinical data of the subjects. All values were expressed as mean \pm standard deviation. The results were evaluated at a significance level of $\mathrm{p}<0.05$.

\section{RESULTS}

Out of 100 patients taken into the study, 3 lost to follow up in both the groups, and 2 patients in metoprolol group and 4 patients in the carvedilol group discontinued intervention due to change in the disease pattern. Therefore, out of 100 patients 88 patients were analysed at the end of the study.

Table 1: Demographic characteristics of the study group.

\begin{tabular}{|lll|}
\hline $\begin{array}{l}\text { Baseline } \\
\text { characteristics }\end{array}$ & $\begin{array}{l}\text { Metoprolol } \\
\text { Sex }\end{array}$ & Carvedilol \\
\hline M:25 & M:28 \\
\hline F:20 & F:15 \\
\hline Mean age & $55.86 \pm 5.86$ & $56.45 \pm 3.21$ \\
\hline Mean height & $67.56 \pm 10.85$ & $67.94 \pm 9.59$ \\
\hline
\end{tabular}

M: Male, F: Female.

Table 2: Routine blood investigations.

\begin{tabular}{|llllll|}
\hline \multirow{2}{*}{ Blood parameters } & \multicolumn{4}{l}{$\begin{array}{l}\text { Metoprolol } \\
\text { (mean } \pm \text { standard deviation) }\end{array}$} & \multicolumn{2}{l}{$\begin{array}{l}\text { Carvedilol } \\
\text { (mean } \pm \text { standard deviation) }\end{array}$} & P value \\
\cline { 2 - 6 } & Baseline & $24^{\text {th }}$ week & Baseline & $24^{\text {th }}$ week & \\
\hline Hemoglobin & $11.77 \pm 1.28$ & $11.87 \pm 0.98$ & $11.28 \pm 1.43$ & $11.47 \pm 1.29$ & NS \\
\hline Total leucocyte count & $7.59 \pm 1.42$ & $7.57 \pm 1.21$ & $7.07 \pm 1.46$ & $7.08 \pm 1.30$ & NS \\
\hline Platelet count & $305.58 \pm 9.45$ & $297.72 \pm 2.01$ & $339.46 \pm 13.66$ & $339.46 \pm 13.66$ & NS \\
\hline Fasting blood sugar & $116.68 \pm 15.08$ & $111.66 \pm 11.44$ & $117.34 \pm 21.15$ & $113.18 \pm 17.83$ & NS \\
\hline Post prandial blood sugar & $153.46 \pm 14.46$ & $149.38 \pm 7.54$ & $149.76 \pm 18.85$ & $141.48 \pm 18.07$ & NS \\
\hline HbA1C & $6.30 \pm 0.61$ & $6.44 \pm 0.39$ & $6.26 \pm 0.82$ & $6.37 \pm 0.69$ & NS \\
\hline Serum sodium & $138.92 \pm 4.95$ & $136.76 \pm 2.93$ & $137.94 \pm 1.68$ & $137.48 \pm 1.33$ & NS \\
\hline Serum potassium & $3.88 \pm 0.61$ & $3.82 \pm 0.53$ & $3.85 \pm 0.23$ & $3.75 \pm 0.18$ & NS \\
\hline Blood urea & $25.44 \pm 4.66$ & $24.56 \pm 3.41$ & $25.58 \pm 3.43$ & $25.62 \pm 3.84$ & NS \\
\hline Serum creatinine & $0.79 \pm 0.22$ & $0.76 \pm 3.41$ & $0.71 \pm 0.21$ & $0.76 \pm 0.13$ & NS \\
\hline Total bilirubin & $0.67 \pm 0.26$ & $0.63 \pm 0.20$ & $0.73 \pm 0.33$ & $0.76 \pm 0.12$ & NS \\
\hline Direct bilirubin & $0.17 \pm 0.06$ & $0.18 \pm 0.04$ & $0.19 \pm 0.08$ & $0.19 \pm 0.05$ & NS \\
\hline SGOT & $29.76 \pm 11.43$ & $27.98 \pm 9.78$ & $28.2 \pm 8.32$ & $26.96 \pm 7.22$ & NS \\
\hline SGPT & $40.62 \pm 12.9$ & $35.64 \pm 11.83$ & $42.48 \pm 10.67$ & $37.98 \pm 10.92$ & NS \\
\hline
\end{tabular}

NS: Not significant, SGOT: Serum glutamic oxaloacetic transaminase, SGPT: Serum glutamic pyruvic transaminase. 
Table 3: Effects of metoprolol and carvedilol on lipid profile.

\begin{tabular}{|llllll|}
\hline \multirow{2}{*}{ Lipid parameters } & \multicolumn{2}{l}{$\begin{array}{l}\text { Metoprolol } \\
\text { (mean } \pm \text { standard deviation) }\end{array}$} & \multicolumn{2}{l}{$\begin{array}{l}\text { Carvedilol } \\
\text { (mean } \pm \text { standard deviation) }\end{array}$} & P value \\
\cline { 2 - 6 } & Baseline & $24^{\text {th }}$ week & Baseline & $24^{\text {th }}$ week & \\
\hline Total cholesterol & $234.22 \pm 18.03$ & $232.22 \pm 16.04$ & $241.52 \pm 28.97$ & $238.36 \pm 26.31$ & NS \\
\hline Serum triglyceride & $159.8 \pm 16.97$ & $160.84 \pm 11.47$ & $160.22 \pm 13.32$ & $145.78 \pm 15.41$ & NS \\
\hline LDL-C & $123.46 \pm 12.42$ & $122.58 \pm 14.71$ & $125.9 \pm 11.32$ & $121.7 \pm 12.7$ & NS \\
\hline HDL-C & $35.28 \pm 9.04$ & $40.84 \pm 9.72$ & $35.8 \pm 9.43$ & $38.7 \pm 9.52$ & NS \\
\hline
\end{tabular}

NS: Nothing significant; LDL-C: Low density lipoprotein cholesterol; HDL-C: High density lipoprotein cholesterol.

Two groups were compared for baseline characteristics of age, sex, height, weight. Both groups had male predominance. Mean age of the patients in the metoprolol group was $55.86 \pm 5.86$ and $56.45 \pm 3.21$ years in the carvedilol group. Average body weight in metoprolol group was $67.56 \pm 10.85$ and average height was $162.22 \pm 6.79 \mathrm{~kg}$. While in carvedilol group average body weight was $67.94 \pm 9.59$ and average height was $162.78 \pm 7.19 \mathrm{~kg}$ as shown in the (Table 1$)$.

Routine blood investigations were done in all the patients and showed in (Table 2).

The lipid parameters like total cholesterol, serum triglyceride, LDL cholesterol and HDL-Cholesterol was assessed at the end of 24 weeks among the patients of both groups, it was revealed that, there was no statistically difference between both the two groups at the end of the study at $24^{\text {th }}$ week as compared to baseline, as described in the (Table 3), but however there was nonsignificant decrease in serum triglyceride in patients on carvedilol at the end of the study.

Tolerability was assessed among the patients in both the groups, which manifested that 9 out of $43(21 \%)$ patients showed side effect with carvedilol whereas 12 out of 45 patients (27\%) showed side effect with metoprolol. Headache was more common in patients taking carvedilol whereas fatigue was more common in patients on metoprolol. It is demonstrated in the (Table 4).

Table 4: Tolerability profile of the study drugs.

\begin{tabular}{|lll|}
\hline Symptoms & $\begin{array}{l}\text { Carvedilol } \\
(\mathbf{n = 4 3}) \mathbf{N}(\boldsymbol{\%})\end{array}$ & $\begin{array}{l}\text { Metoprolol } \\
(\mathbf{n = 4 5}) \mathbf{N}(\%)\end{array}$ \\
\hline Dizziness & $2(4.44)$ & $1(2.32)$ \\
\hline Headache & $3(6.67)$ & $2(4.65)$ \\
\hline Fatigue & $1(2.22)$ & $3(6.97)$ \\
\hline Gastroenteritis & 0 & 0 \\
\hline $\begin{array}{l}\text { Peripheral } \\
\text { edema }\end{array}$ & 0 & $1(2.32)$ \\
\hline Weight gain & $1(2.22)$ & $2(4.65)$ \\
\hline Nausea & $1(2.22)$ & $1(2.32)$ \\
\hline Cough & $1(2.22)$ & $1(2.32)$ \\
\hline Athralgia & 0 & $1(2.32)$ \\
\hline Rashes & 0 & 0 \\
\hline Total & $9(21)$ & $12(27)$ \\
\hline
\end{tabular}

\section{DISCUSSION}

The main aim of treatment of stable angina pectoris is to reduce cardiac work load and oxygen requirements. Beta blockers are one of the important class of drugs indicated for the treatment of stable angina pectoris. They do it by reducing myocardial oxygen demand by inhibiting the increases in heart rate, arterial pressure, and myocardial contractility caused by adrenergic activation. Our study has demonstrated that there was no significant difference between two groups in terms of routine hematological parameters, but there was decrease in serum triglyceride in carvedilol group which was non-significant whereas no change was observed in metoprolol group. The mechanism for these are poorly understood but multiple hypotheses have been put up for above which includes; $\alpha 1$-adrenergic receptor blockade, vasodilatation, reduced oxidative stress, anti-inflammatory activity: Carvedilol is associated with antioxidant activity possibly attributable to stimulation of endothelial NO production or reduced NO inactivation. ${ }^{3}$ Carvedilol also inhibits LDL-C oxidation, potentially reducing the accumulation of oxidized LDL-C in vessel walls and subsequent vascular damage. Furthermore, carvedilol has been shown to protect against ROS via scavenging of free radicals, suppression of free radical generation, and prevention of ferric ion-induced oxidation. ${ }^{4}$ Furthermore, $\alpha 1$-receptor blockade caused by carvedilol increases the availability of lipoprotein lipase for triglyceride hydrolysis and in liver by modulating TG efflux and cholesterol synthesis, enhances LDL binding to its hepatic receptors. The net result is that serum glucose and triglycerides decrease and HDL-C is increased. ${ }^{5,6}$ It is possible that carvedilol has independently exerted the above effects on lipid profile. In many of the previous studies, it was demonstrated that metoprolol and carvedilol lead to change in lipid and glucose parameters. ${ }^{7,8}$ Furthermore, previous studies were different to our study in terms of studied population, disease condition, administered drugs, and duration of intervention. Longer periods may indicate long-term changes, but the variability of results increases due to changes in patient's condition, diet, prescribed medications, and lack of compliance.

\section{CONCLUSION}

In this prospective study comparing the metoprolol and carvedilol, we propose that, both the drugs have not caused changes in hematological parameters including 
routine blood investigations, HbA1C. Carvedilol has shown improvement in serum triglyceride i.e., better lipid profile than metoprolol, although no derangement of lipid parameters were observed with metoprolol Both the drugs shown good tolerability which is showed by less side effect profile in all the patients.

Funding: No funding sources

Conflict of interest: None declared

Ethical approval: The study was approved by the Institutional Ethics Committee

\section{REFERENCES}

1. Gupta R, Mohan I, Narula J. Trends in Coronary Heart Disease Epidemiology in India. Ann Glob Heal. 2016;82(2):307-15.

2. Ford TJ, Corcoran D, Berry C. Stable coronary syndromes: Pathophysiology, diagnostic advances and therapeutic need. Heart. 2018;104(4):284-92.

3. Dandona P, Ghanim H, Brooks DP. Antioxidant activity of carvedilol in cardiovascular disease. J Hypertens. 2007;25(4):731-41.

4. Fonseca VA. Effects of $\beta$-blockers on glucose and lipid metabolism. Curr Med Res Opin. 2010;26(3):615-29.
5. Sharp RP, Sirajuddin R, Sharief IM. Impact of carvedilol on the serum lipid profile. Ann Pharmacother. 2008;42(4):564-71.

6. Ayashi S, Assareh AR, Jalali MT, Olapour S, Yaghooti $H$. Role of antioxidant property of carvedilol in mild to moderate hypertensive patients: A prospective open - label study. Indian J Pharmacol. 2016;1:372-6.

7. Bell DSH, Bakris GL, Gill MJB. Comparison of carvedilol and metoprolol on serum lipid concentration in diabetic hypertensive patients. Diabetes, Obes Metab. 2009;11(3):234-8.

8. Ozbilen S, Eren MA, Turan MN, Sabuncu T. The impact of carvedilol and metoprolol on serum lipid concentrations and symptoms in patients with hyperthyroidism. Endocr Res. 2012;37(3):117-23.

Cite this article as: Bansal M, Gari M, Varshney M. A comparative assessment of safety and tolerability of metoprolol versus carvedilol in patients of chronic stable angina. Int J Basic Clin Pharmacol 2020;9:792-5. 